\title{
The effects of GLP-1 analogues on pre-diabetes of the children
}

\author{
QING-XIA ZHOU $^{1}$, ZI-YU WANG $^{2}$, HUA-FENG ZHAO $^{1}$ and SHAN WANG $^{3}$ \\ ${ }^{1}$ Department of Pediatrics, Weifang People's Hospital, Weifang, Shandong 261041; \\ ${ }^{2}$ Department of Radiology, Yidu Central Hospital of Weifang, Weifang, Shandong 262500; \\ ${ }^{3}$ Department of Pediatrics, People's Hospital of Shouguang City, Shouguang, Shandong 262700, P.R. China
}

Received September 5, 2016; Accepted November 29, 2016

DOI: $10.3892 / \mathrm{etm} .2017 .4129$

\begin{abstract}
The aim of the study was to evaluate the clinical efficacy of glucagon-like peptide-1 (GLP-1) analogues in children of pre-diabetes to delay or reverse the development of pre-diabetes into the state of diabetes by early intervention. Prospective and randomized controlled clinical trials were performed in 42 cases of newly diagnosed pre-diabetes in children. The sample size was randomly divided into the two groups. The first group included 21 subjects comprising the lifestyle intervention group, i.e., control group, and the second group included 21 subjects comprising the lifestyle intervention+GLP-1 analogues liraglutide group, i.e., observation group. Interventions carried out lasted 3 months. A review of intervention was carried out at 1 month and after 3 months. Medical examinations were carried out at the the time following diagnosis with pre-diabetes and after the intervention of 3 months. The medical test examinations included the fasting blood glucose (FPG), 2-hour postprandial blood glucose (2hPG), detection of glycated hemoglobin A1c (HbA1C), total cholesterol (TC), triglyceride (TG), low-density lipoprotein cholesterol (LDL-C), high-density lipoprotein cholesterol (HDL-C), body mass index (BMI), insulin resistance (IR) and the islet cell functions. After 1 month of intervention, the observation group exhibited a better control on FPG and $2 \mathrm{hPG}$ compared with the control group $(\mathrm{P}<0.05)$. After 3 months of the intervention, FPG and 2hPG levels of the observation group were significantly lower than those of the control group $(\mathrm{P}<0.01)$. The levels of HbA1C, TC, TG, LDL-C, HDL-C, and BMI of the observation group were statistically better controlled, when compared with the control group after the intervention of 3 months. The IR index of the observation group was significantly decreased compared to that of the control group $(\mathrm{P}<0.05)$ and the islet function index of the $\beta$-cell of the observation group showed statistically higher values than that of the control group $(\mathrm{P}<0.05)$. In conclusion, GLP-1 analogues are a better regulator of blood sugar levels, effectively improve lipid profile, body mass, IR and islet $\beta$-cell
\end{abstract}

Correspondence to: Dr Hua-Feng Zhao, Department of Pediatrics, Weifang People's Hospital, Weifang, Shandong 261041, P.R. China E-mail: hifdsecw2382@163.com

Key words: GLP-1 analogues, pre-diabetes, liraglutide, children function. Furthermore, GLP-1 analogues opens up a new way to intervene pre-diabetes in children.

\section{Introduction}

Pre-diabetes ('intermediate hyperglycaemia') is based on glycaemic parameters above normal but below diabetes thresholds considered to be a high-risk state for diabetes with an annualized conversion rate of $5-10 \%$, with a similar proportion converting back to normoglycaemia (1). Multifactorial risk scores may optimize the estimation of diabetes risk using non-invasive parameters and blood-based metabolic features in addition to glycaemic values. For prediabetic individuals, lifestyle modification is the cornerstone of diabetes prevention.

At present, the prevalence of diabetes mellitus (DM) and type 2 DM (T2DM) in children has significantly increased (2). To the best of our knowledge, few reports have focused on early intervention for children with DM and even literature based on pre-diabetic children intervention with regard to lifestyle is limited. The present study was conducted to evaluate the effect of glucagon-like peptide-1 (GLP-1) analogues for reversal of normal blood glucose in patients with pre-diabetes.

\section{Materials and methods}

Subjects. In total, 42 children diagnosed with pre-diabetes visited the outpatients of the Department of Endocrinology of Weifang People's Hospital. All the samples were selected from the period of April 2015 to April 2016, and patients were aged 6-18 years. Out of 42 children, 29 subjects were male and 13 subjects were female. Ethical clearance for the study was obtained from the Institutional Ethics Board of Weifang People's Hospital. Informed patient consent was also obtained from all the subjects.

Exclusion criteria. Any children with genetic metabolism, endocrine disease, kidney disease high blood pressure and high blood lipid profile were excluded from the study.

General information of both groups of patients is shown in Table I and the diagnostic criteria for the early stage of DM and dyslipidemia are shown in Table II.

The children were randomly divided into the intervention group (control group) and the lifestyle intervention+GLP-1 analogues liraglutide group (observation group). 
Table I. General information of both the groups of patients.

\begin{tabular}{lcccrr}
\hline Group & Cases, no. & Gender, male/female & Age & BMI, $\mathrm{kg} / \mathrm{m}^{2}$ & $\mathrm{HbA} 1 \mathrm{c}, \%$ \\
\hline Control & 21 & $15 / 6$ & $11.12 \pm 2.10$ & $30.89 \pm 5.02$ & $5.85 \pm 1.33$ \\
Observation & 21 & $14 / 7$ & $11.19 \pm 2.27$ & $30.98 \pm 4.97$ & $5.87 \pm 1.35$
\end{tabular}

Gender, age, BMI and HbA1c were compared in the two groups of children, and P>0.05 indicated that they were comparable. BMI, body mass index; HbA1c, hemoglobin A1c.

Table II. Diagnostic criteria of DM in the early stage and dyslipidemia.

\begin{tabular}{lccccc}
\hline & $\begin{array}{c}\text { DM and DM } \\
\text { pre-diagnostic criteria, mmol/1 }\end{array}$ & & & $\begin{array}{c}\text { Diagnostic criteria for } \\
\text { dyslipidemia, mmol/1 }\end{array}$ \\
\hline IFG & IGT & DM & High TG & High TC & Low HDL-C \\
\hline $\begin{array}{l}\text { FPG: (5.6-6.9), while OGTT } \\
2 \text { h blood glucose }<7.8\end{array}$ & $\begin{array}{c}\text { OGTT 2 h blood glucose } \\
(7.8-11.0), \text { while FPG }<5.6\end{array}$ & $\begin{array}{c}\text { FPG } \geq 7.0 \text { or OGTT 2 h } \\
\text { blood glucose }>11.1\end{array}$ & $\geq 1.7$ & $\geq 5.2$ \\
\hline
\end{tabular}

DM, diabetes mellitus; FPG, fasting blood glucose; IFG, impaired fasting glucose; IGT, impaired glucose tolerance; OGTT, oral glucose tolerance test; TG, triglyceride; TC, total cholesterol; HDL-C, high-density lipoprotein cholesterol.

In the lifestyle intervention group, all the children followed a unified diet exercise prescription with regular telephonic conversation, outpatient follow-up, and education of the parents and children at the same time.

For the observation group, Liraglutide Injection (18 mg/piece; Novo Nordisk, Copenhagen, Denmark) treatment was administered. The initial dose was $0.6 \mathrm{mg} /$ day subcutaneous injection, administered daily. After 1 week it was adjusted to $1.2 \mathrm{mg} /$ day subcutaneous injection, daily, followed by $1.2 \mathrm{mg} /$ day maintenance therapy for $\leq 3$ months.

Determination of fasting height and weight of children was obtained manually. After $10 \mathrm{~h}$ of fasting, the next morning, venous blood indexes including fasting blood glucose (FPG), hemoglobin A1c (HbA1C), total cholesterol (TC), triglyceride (TG), low-density lipoprotein cholesterol (LDL-C), high-density lipoprotein cholesterol (HDL-C), fasting insulin (FINS), $2 \mathrm{~h}$ postprandial blood glucose (2hPG) were measured and oral glucose tolerance test was taken as a diagnostic test for DM. After $10 \mathrm{~h}$ of fasting, oral glucose was taken as $1.75 \mathrm{~g} / \mathrm{kg}, \leq 75 \mathrm{~g} / \mathrm{time}$. All other diagnostic methods of DM including TC, enzymatic measurement, LDL-C, HDL-C, direct method of measurement, FPG, measurement by the sugar kinase method, body mass index (BMI), homeostasis model assessment for $\beta$-cell function index (HOMA- $\beta$ ) and insulin resistance index (HOMA-IR) were calculated.

BMI was calculated as weight $\mathrm{kg} /$ height $\mathrm{m}^{2}$. HOMA- $\beta$ was calculated as $=20 \mathrm{x}$ FINS/(FPG-3.5). IR was calculated by homeostasis model assessment (HOMA), and HOMA was calcaluted as HOMA-IR $=($ FPG mmol/1 x FINS mU/1/22.5 $)$. A HOMA-IR value of $<4$ indicated prompted high insulin sensitivity, whereas if the HOMA-IR value was $>4$, it indicated prompted low insulin sensitivity and high IR (3).
Statistical analysis. SPSS1 8.0 software (SPSS, Inc., Chicago, IL, USA) was used for statistics and analysis of data. Data of normal distribution were recorded as mean \pm standard deviation. HOMA- $\beta$ was transformed into normal data for analysis. Measurement data between the two groups were tested by t-test. The analysis before and after treatment was performed using paired t-test. $\mathrm{P}<0.05$ was considered to indicate a statistically significant difference.

\section{Results}

Analysis of blood glucose metabolism of the two groups before and after the intervention. FPG levels of the two groups were compared before the intervention and after the 1 and 3 months of the intervention. After 1 month of intervention, the FPG in the observation group was $6.11 \pm 0.78 \mathrm{mmol} / 1$, which was lower than that in the control group $(6.21 \pm 1.21 \mathrm{mmol} / \mathrm{l})(\mathrm{P}<0.05)$. After 3 months of intervention, the FPG $(0.01 \pm 0.66 \mathrm{mmol} / \mathrm{l})$ in the observation group was significantly lower than that in the control group $(6.12 \pm 1.08 \mathrm{mmol} / \mathrm{l})$. The difference was statistically significant $\mathrm{P}<0.01$ (Fig. 1).

Glucose levels after the 2- $h$ glucose loading. We compared the blood glucose levels after $2 \mathrm{~h}$ of glucose loading between the two groups. After 1 month of intervention with $2 \mathrm{~h}$ of glucose loading, the blood glucose $(7.22 \pm 2.01 \mathrm{mmol} / \mathrm{l})$ in the observation group was lower than that in the control group $(7.89 \pm 1.97 \mathrm{mmol} / \mathrm{l})$. The difference was not significant $(\mathrm{P}>0.05)$. After 3 months of intervention with after $2 \mathrm{~h}$ of glucose loading, the blood glucose $(6.15 \pm 1.67 \mathrm{mmol} / \mathrm{l})$ in the observation group was significantly lower than that of the control group $(7.63 \pm 1.82 \mathrm{mmol} / \mathrm{l})$. The difference was significant $(\mathrm{P}<0.01)$ (Fig. 2). 


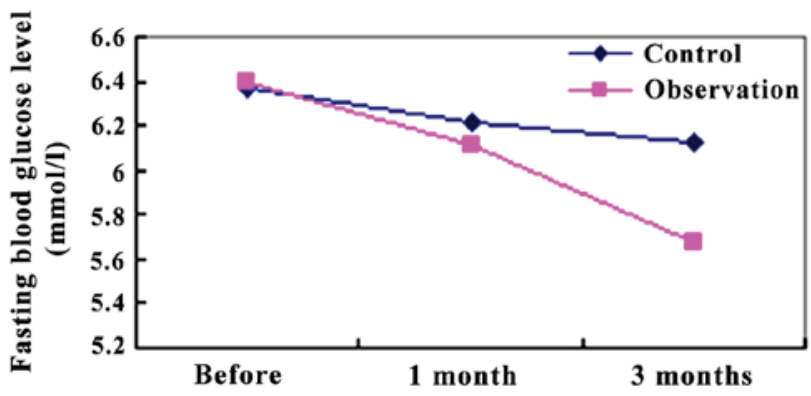

Figure 1. Comparison of fasting blood glucose level between the two groups.

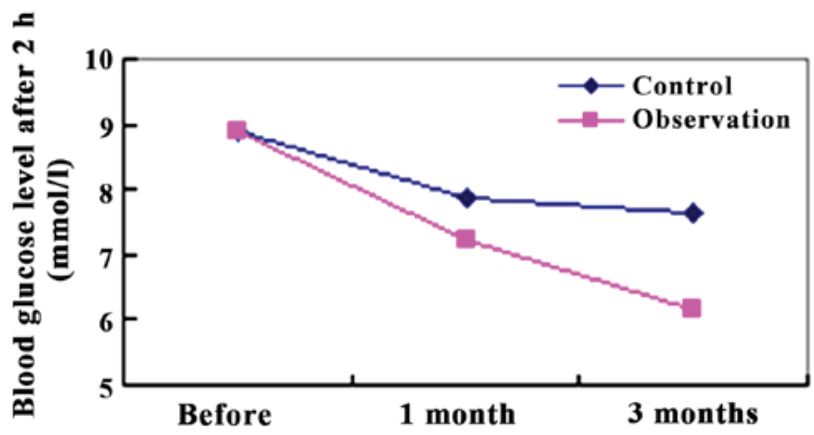

Figure 2. Comparison of blood glucose level of the two groups after $2 \mathrm{~h}$ of glucose loading.

HbAlC levels in the two groups. At the HbA1C level, the observation group was $5.87 \pm 1.35 \%$ and the control group was $5.85 \pm 1.33 \%$. No significant difference in HbA1C levels between the two groups was observed $(\mathrm{P}>0.05)$. After 3 months of intervention, the HbA1C level in the observation group was $5.23 \pm 1.01 \%$, which was significantly lower than that in the control group at $5.56 \pm 1.14 \%(\mathrm{P}<0.01)$ (Fig. 3).

The serum lipid profile and BMI levels were analyzed in the two groups before and after the intervention. BMI, TC, TG, LDL-C, HDL-C, and FINS of the observation group revealed statistically significant results, when compared with the control group $(\mathrm{P}<0.05)$. Referring to the Chinese BMI criteria (7-18 years of age) and CDC 2000 criteria of the United States (6 years of age), children in the group were mostly overweight and obese, with the cumulative incidence at $\leq 83.33 \%(35 / 42$ cases) (Table III).

Comparison of the level of HOMA-IR and HOMA- $\beta$. The levels of HOMA-IR and HOMA- $\beta$ were analyzed before and after intervention in the two groups. The decreased IR index of the observation group was higher than that of the control group, and the difference was statistically significant $(\mathrm{P}<0.05)$. Islet function index of the $\beta$-cell of the observation group was significantly higher than that of the control group, and the difference was statistically significant $(\mathrm{P}<0.05)$ (Table IV).

\section{Discussion}

The results of the present study showed a total of $\leq 83.33 \%$ (35/42 cases) of obese and overweight children in the early stage of DM. Lifestyle changes reduced physical activity and unhealthy eating habits have caused an increased obesity

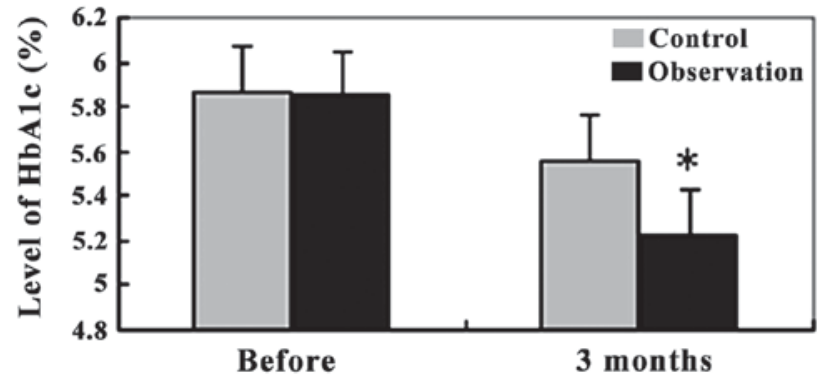

Figure 3. Comparison of hemoglobin A1c (HbA1C) between the two groups. *Compared with control group for 3 months, $\mathrm{P}<0.05$.

incidence. In fact, approximately 110 million of the world's children are overweight or obese (5). Related findings also showed that compared with normal children, overweight and obese children had higher average blood glucose levels, blood glucose abnormalities, impaired glucose tolerance (IGT) and diabetes incidence (6). BMI in children with T2DM was elevated, while BMI and IR in childhood appeared simultaneously (7). The sensitivity of insulin was negatively correlated with BMI and obesity. Children with increased BMI revealed decreased insulin sensitivity and increased blood glucose level that resulted in impaired glucose metabolism. The period of normal glucose tolerance and hyperlipidemia are considered to be the early stage of DM (8). There are three stages of glucose metabolism in children and adolescents: Hyperinsulinemia, pre-DM and DM stage. The early stage of diabetes refers to the impaired glucose regulation between normal glucose metabolism and DM, including impaired fasting glucose (IFG), IGT, and IFG/IGT. Previous results obtained from China show 148 million individuals in the early stage of diabetes, thereby increasing the incidence rate to $\leq 15.5 \%$ (9). Approximately $70 \%$ of the patients of the early stage of diabetes eventually progress into diabetes, which is harmful for the population. Overweight, obesity and decreased physical activity of children with diabetes means they are at greater risk of developing diabetes. Over the past 40 years, there have been 8 large-scale clinical trials showing that $25-60 \%$ of pre-diabetes patients can prevent the development of diabetes by merely lifestyle intervention (9). In order to prevent the development of obesity in children, the key is how to prevent the development of obesity through early control. By changing the lifestyle such as introducing a proper diet plan and adequate exercise therapy, the conversion of pre-diabetes into diabetes may be preveted. Change of lifestyle is considered to be the cornerstone in the treatment of pre-diabetes. However, it is generally believed that the long-term effectiveness of lifestyle intervention is not good, and it is easy to rebound. Even if the body mass is reduced, there is a $40-50 \%$ likelihood that the IGT damages may cause T2DM (10). Therefore, lifestyle intervention alone cannot completely prevent the occurrence and development of diabetes. Few reports are available regarding the long-term effectiveness of only lifestyle intervention for the obese children. The practicability of only lifestyle intervention is poor, and is widely questioned by doctors and patients. In view of the particularity of school age children, due to the lack of self-discipline in children, the simple lifestyle intervention may be difficult in achieving individual weight 
Table III. Blood lipids and fasting insulin were compared between the two groups.

\begin{tabular}{|c|c|c|c|c|}
\hline \multirow[b]{2}{*}{ Index } & \multicolumn{2}{|c|}{ Control group } & \multicolumn{2}{|c|}{ Observation group } \\
\hline & Enrollment & Intervention for 3 months & Enrollment & Intervention for 3 months \\
\hline BMI, $\mathrm{kg} / \mathrm{m}^{2}$ & $30.89 \pm 5.02$ & $29.88 \pm 5.32^{\mathrm{a}}$ & $30.98 \pm 4.97$ & $28.68 \pm 5.19^{\mathrm{a}, \mathrm{b}}$ \\
\hline FINS, $\mu \mathrm{U} / \mathrm{ml}$ & $31.21 \pm 8.01$ & $28.82 \pm 9.64^{\mathrm{a}}$ & $31.19 \pm 8.11$ & $26.79 \pm 9.69^{\mathrm{a}, \mathrm{b}}$ \\
\hline $\mathrm{TG}, \mathrm{mmol} / \mathrm{l}$ & $1.13 \pm 0.72$ & $1.10 \pm 0.39$ & $1.14 \pm 0.62$ & $1.04 \pm 0.37^{\mathrm{a}, \mathrm{b}}$ \\
\hline $\mathrm{TC}, \mathrm{mmol} / \mathrm{l}$ & $4.19 \pm 1.26$ & $3.95 \pm 1.03^{\mathrm{a}}$ & $4.17 \pm 1.27$ & $3.80 \pm 1.01^{\mathrm{a}, \mathrm{b}}$ \\
\hline $\mathrm{HDL}, \mathrm{mmol} / \mathrm{l}$ & $1.18 \pm 0.31$ & $1.20 \pm 0.19$ & $1.19 \pm 0.24$ & $1.33 \pm 0.25^{\mathrm{a}, \mathrm{b}}$ \\
\hline $\mathrm{LDL}, \mathrm{mmol} / \mathrm{l}$ & $2.45 \pm 1.00$ & $2.39 \pm 0.66$ & $2.47 \pm 0.96$ & $2.21 \pm 0.88^{\mathrm{a}, \mathrm{b}}$ \\
\hline
\end{tabular}

The blood lipid profile of the two groups of children was compared at enrollment, $\mathrm{P}>0.05$, when compared. Compared with before intervention, ${ }^{\mathrm{a}} \mathrm{P}<0.05$. The observation group was compared with the control group, ${ }^{\mathrm{b}} \mathrm{P}<0.05$. BMI, body mass index; FINS, fasting insulin; TG, triglyceride; $\mathrm{TC}$, total cholesterol; HDL, high-density lipoprotein; LDL, low-density lipoprotein.

Table IV. Comparison of the changes of HOMA-IR and HOMA- $\beta$ in the two groups after 3 months of intervention.

\begin{tabular}{lccc}
\hline Index & $\begin{array}{c}\text { Cases, } \\
\text { no. }\end{array}$ & $\begin{array}{c}\text { Control } \\
\text { group }\end{array}$ & $\begin{array}{c}\text { Observation } \\
\text { group }\end{array}$ \\
\hline $\begin{array}{l}\text { HOMA-IR } \\
\text { of enrollment } \\
\text { HOMA-IR } \\
\text { after 3 months }\end{array}$ & 21 & $7.04 \pm 2.73$ & $7.06 \pm 2.68$ \\
$\begin{array}{l}\text { HOMA- } \beta \\
\text { of enrollment }\end{array}$ & 21 & $6.52 \pm 3.51^{\mathrm{a}}$ & $6.02 \pm 3.11^{\mathrm{a}, \mathrm{b}}$ \\
$\begin{array}{l}\text { HOMA-IR } \\
\text { after 3 months }\end{array}$ & 21 & $2.56 \pm 0.37$ & $2.46 \pm 0.31^{\mathrm{a}, \mathrm{b}}$ \\
\hline
\end{tabular}

HOMA-IR and HOMA- $\beta$ of the two groups of children were compared at enrollment, $\mathrm{P}>0.05$, when compared. Compared with before intervention, ${ }^{\mathrm{a}} \mathrm{P}<0.05$. The observation group was compared with the control group, ${ }^{\mathrm{b}} \mathrm{P}<0.05$. HOMA-IR, homeostasis model for assessment of insulin resistance.

loss because of its inability to achieve the amount of physical activity. On the other hand, considering the children's stage, calorie-restricted intake affects their growth and development, leading to the fact that the only simple lifestyle intervention cannot be implemented to reduce obesity. Consequently, early drug intervention programmes are correctly becoming more popular.

GLP-1 belongs to the gut peptide hormone secreted by intestinal epithelial L cells. GLP-1, the incretin hormone regulates appetite, delaying gastric emptying, stimulating islet $\beta$-cell proliferation, suppressing apoptosis, promoting insulin secretion, improving insulin sensitivity, fat mobilization, and restoring the function of islet $\beta$-cells. Due to its main role in a number of metabolic activities, GLP-1 peptide has become a hot topic in the study of obesity and diabetes prevention $(11,12)$. Natural GLP-1 has a half-life of only 1-2 min and can be rapidly degraded by DPP-4 in vivo. After the degradation it became inactive, further hindering its clinical application. The GLP-1 analogues have a long half-life, which is not easily degraded and has the physiological function of GLP-1 to be applied in clinical practice (repeated). The representative drugs of GLP-1 peptide are exenatide and liraglutide. The peptide is the first GLP-1 analogue used for the treatment of T2DM. Previous studies revealed that the twice a day dose of exenatide subcutaneous injection and daily one dose of liraglutide subcutaneous injection, plays an important role in the regulation of blood sugar, reduction in weight, protection of islet $\beta$-cells and the prevention of cardiovascular disease (13-19). LEAD results showed that liraglutide administered alone or in combination with other antidiabetic drugs, effectively improved the blood glucose level, and controlled the pancreatic $\beta$-cell function as well as weight loss with less risk of hypoglycemia (20-25). When the glucose concentration was lower than $4.5 \mathrm{mmol} / \mathrm{l}$, GLP-1 lost its hypoglycemic effect (21).

As the early application of GLP-1 analogues may reverse the early development of diabetes, this study used a prospective randomized controlled trial to compare the blood glucose, lipid profile, body weight, IR and $\beta$-cell function of pre-diabetic children after the intervention of 3 months in simple lifestyle intervention group (control group) and lifestyle intervention+GLP-1 analogue liraglutide treatment group (observation group). After 1 month of intervention, 2hPG and FPG in the observation group were lower than those in the control group $(\mathrm{P}<0.05)$. After 3 months, FPG and $2 \mathrm{hPG}$ of the observation group were significantly lower than those of the control group $(\mathrm{P}<0.01)$. After the 3 months of intervention, HbA1C, TC, TG, LDL-C, HDL-C, and BMI of the observation group were statistically different compared with the control group $(\mathrm{P}<0.05)$. The decreased IR index of the observation group was significantly higher than that of the control group $(\mathrm{P}<0.05)$. The islet function index of the $\beta$-cell of the observation group was significantly higher than that of the control group $(\mathrm{P}<0.05)$. GLP-1 analogues can control FPG, 2hPG blood glucose in early stages, improve blood lipid profile, improve BMI and IR, and improve the function of islet $\beta$-cell, while exploring new ways of early childhood intervention. In view of the current domestic and international use of GLP-1 powder injection of the long-acting analogue of chemical synthesis, with complex production process, high cost, expensive market price, storage and transportation difficulties, and 
inconvenience of subcutaneous administration, thus, clinical feasibility is not ideal. Therefore, we need to improve the production mode of GLP-1 similar peptide, change the way of using GLP-1 similar peptide, and develop GLP-1 similar peptide of high efficiency, that is cost effective and easy to use, in order to obtain good social benefits.

\section{References}

1. American Diabetes Association: Standards of medical care in diabetes - 2010. Diabetes Care 33 (Suppl 1): S11-S61, 2010.

2. Amed S, Daneman D, Mahmud FH and Hamilton J: Type 2 diabetes in children and adolescents. Expert Rev Cardiovasc Ther 8: 393-406, 2010.

3. American Diabetes Association: Diagnosis and classification of diabetes mellitus. Diabetes Care 35 (Suppl 1): S64-S71, 2012.

4. Matthews DR, Hosker JP, Rudenski AS, Naylor BA, Treacher DF and Turner RC: Homeostasis model assessment: Insulin resistance and beta-cell function from fasting plasma glucose and insulin concentrations in man. Diabetologia 28: 412-419, 1985.

5. Haslam DW and James WP: Obesity. Lancet 366: 1197-1209, 2005.

6. Rush EC, Plank LD, Mitchelson E and Laulu MS: Central obesity and risk for type 2 diabetes in Maori, Pacific, and European young men in New Zealand. Food Nutr Bull 23 (Suppl 3): 82-86, 2002.

7. Brosnan CA, Upchurch S and Schreiner B: Type 2 diabetes in children and adolescents: An emerging disease. J Pediatr Health Care 15: 187-193, 2001.

8. Craig ME, Hattersley A and Donaghue KC: Definition, epidemiology and classification of diabetes in children and adolescents. Pediatr Diabetes 10 (Suppl 12): 3-12, 2009.

9. Yang W, Lu J, Weng J, Jia W, Ji L, Xiao J, Shan Z, Liu J, Tian H, Ji Q, et al; China National Diabetes and Metabolic Disorders Study Group: Prevalence of diabetes among men and women in China. N Engl J Med 25: 1090-1101, 2010.

10. Weerakiet S, Srisombut C, Bunnag P, Sangtong S, Chuangsoongnoen $\mathrm{N}$ and Rojanasakul A: Prevalence of type 2 diabetes mellitus and impaired glucose tolerance in Asian women with polycystic ovary syndrome. Int J Gynaecol Obstet 75: 177-184, 2001

11. D'Alessio DA and Vahl TP: Glucagon-like peptide 1: Evolution of an incretin into a treatment for diabetes. Am J Physiol Endocrinol Metab 286: E882-E890, 2004.

12. Theodorakis MJ, Carlson O, Michopoulos S, Doyle ME, Juhaszova M, Petraki K and Egan JM: Human duodenal enteroendocrine cells: Source of both incretin peptides, GLP-1 and GIP. Am J Physiol Endocrinol Metab 290: E550-E559, 2006.

13. Deacon CF, Nauck MA, Toft-Nielsen M, Pridal L, Willms B and Holst JJ: Both subcutaneously and intravenously administered glucagon-like peptide I are rapidly degraded from the NH2-terminus in type II diabetic patients and in healthy subjects. Diabetes 44: 1126-1131, 1995.

14. Buse JB, Henry RR, Han J, Kim DD, Fineman MS and Baron AD; Exenatide-113 Clinical Study Group: Effects of exenatide (exendin-4) on glycemic control over 30 weeks in sulfonylurea-treated patients with type 2 diabetes. Diabetes Care 27: 2628-2635, 2004.
15. DeFronzo RA, Ratner RE, Han J, Kim DD, Fineman MS and Baron AD: Effects of exenatide (exendin-4) on glycemic control and weight over 30 weeks in metformin-treated patients with type 2 diabetes. Diabetes Care 28: 1092-1100, 2005.

16. Kendall DM, Riddle MC, Rosenstock J, Zhuang D, Kim DD, Fineman MS and Baron AD: Effects of exenatide (exendin-4) on glycemic control over 30 weeks in patients with type 2 diabetes treated with metformin and a sulfonylurea. Diabetes Care 28: 1083-1091, 2005.

17. Bunck MC, Diamant M, Cornér A, Eliasson B, Malloy JL, Shaginian RM, Deng W, Kendall DM, Taskinen MR, Smith U, et al: One-year treatment with exenatide improves beta-cell function, compared with insulin glargine, in metformin-treated type 2 diabetic patients: A randomized, controlled trial. Diabetes Care 32: 762-768, 2009.

18. Russell-Jones D: Molecular, pharmacological and clinical aspects of liraglutide, a once-daily human GLP-1 analogue. Mol Cell Endocrinol 15: 137-140, 2009

19. Astrup A, Carraro R, Finer N, Harper A, Kunesova M, Lean ME, Niskanen L, Rasmussen MF, Rissanen A, Rössner S, et al: NN8022-1807 Investigators: Safety, tolerability and sustained weight loss over 2 years with the once-daily human GLP-1 analog, liraglutide. Int J Obes (Lond) 36: 843-854, 2012

20. Marre M, Shaw J, Brändle M, Bebakar WM, Kamaruddin NA, Strand J, Zdravkovic M, Le Thi TD and Colagiuri S; LEAD-1 SU study group: Liraglutide, a once-daily human GLP-1 analogue, added to a sulphonylurea over 26 weeks produces greater improvements in glycaemic and weight control compared with adding rosiglitazone or placebo in subjects with type 2 diabetes (LEAD-1 SU). Diabet Med 26: 268-278, 2009.

21. Nauck M, Frid A, Hermansen K, Shah NS, Tankova T, Mitha IH, Zdravkovic M, Düring M and Matthews DR; LEAD-2 Study Group: Efficacy and safety comparison of liraglutide, glimepiride, and placebo, all in combination with metformin, in type 2 diabetes: The LEAD (liraglutide effect and action in diabetes)-2 study. Diabetes Care 32: 84-90, 2009.

22. Garber A, Henry R, Ratner R, Garcia-Hernandez PA, Rodriguez-Pattzi H, Olvera-Alvarez I, Hale PM, Zdravkovic M and Bode B; LEAD-3 (Mono) Study Group: Liraglutide versus glimepiride monotherapy for type 2 diabetes (LEAD-3 Mono): a randomised, 52-week, phase III, double-blind, parallel-treatment trial. Lancet 373: 473-481, 2009.

23. Zinman B, Gerich J, Buse JB, Lewin A, Schwartz S, Raskin P, Hale PM, Zdravkovic $M$ and Blonde L; LEAD-4 Study Investigators: Efficacy and safety of the human glucagon-like peptide-1 analog liraglutide in combination with metformin and thiazolidinedione in patients with type 2 diabetes (LEAD-4 Met+TZD). Diabetes Care 32: 1224-1230, 2009.

24. Russell-Jones D, Vaag A, Schmitz O, Sethi BK, Lalic N, Antic S, Zdravkovic M, Ravn GM and Simó R; Liraglutide Effect and Action in Diabetes 5 (LEAD-5) met+SU Study Group: Liraglutide vs insulin glargine and placebo in combination with metformin and sulfonylurea therapy in type 2 diabetes mellitus (LEAD-5 met+SU): A randomised controlled trial. Diabetologia 52: 2046-2055, 2009.

25. Buse JB, Rosenstock J, Sesti G, Schmidt WE, Montanya E, Brett JH, Zychma M and Blonde L; LEAD-6 Study Group: Liraglutide once a day versus exenatide twice a day for type 2 diabetes: a 26-week randomised, parallel-group, multinational, open-label trial (LEAD-6). Lancet 374: 39-47, 2009. 